\title{
Magnesium pemoline: Enhancement of spontaneous motor activity'
}

\author{
JOHN J. BOITANO 2 AND JOAN C. BOITANO \\ CENTER FOR BRAIN RESEARCH, UNIVERSITY OF ROCHESTER
}

\begin{abstract}
Magnesium pemoline, a mild central nervous system stimulant, increased spontaneous motor activity in rats within 35 min after injection. The effects persisted throughout the 30 min period of observation. Three days later, during the postdrug phase, the drug group exhibited less activity than the control group. If valid, this "rebound" phenomenon may be explained by a central homeostatic inhibitory mechanism which limits overt activity after a period of prolonged hyperexcitability.
\end{abstract}

Since Plotnikoff's (1966) initial experiment reporting that magnesium pemoline facilitated learning in a jumpout avoidance situation, there have been at least three studies (Beach \& Kimble, 1967; Frey \& Polidora, 1967; Powell et al, 1967) also reporting enhanced acquisition of an active avoidance response and one (Cyert et al, 1967) reporting no effect. In addition, Gurowitz et al (1967) found that magnesium pemoline disrupted learning in a passive avoidance situation requiring an inhibition of responding. Lubar et al (1967), using the Hebb-Williams maze, reported a decrease in error scores which disappeared when both drug and placebo animals were equated for time through covariance procedures.

In all of the above studies reporting significant differences between drug and control Ss, the data may be explained more parsimoniously by positing that magnesium pemoline enhanced spontaneous activity. Beach \& Kimble (1967) found a delayed but nonetheless significant effect of magnesium pemoline on activity as measured in an accelerometer device. Rats were given six 45-sec trials spaced $20 \mathrm{~min}$ apari. During the middle 15 sec a buzzer was presented. No significant differences were found on Trial 1. However, by Trial 6, there were significant differences between the drug and placebo Ss on activity and responsivity to the buzzer. These authors suggested that the drug's stimulant effects were time dependent, with its major activation occurring 50 to 130 min after injection. The purpose of the present experiment was to test the stimulant properties of magnesium pemoline in another type of activity situation and to examine the immediacy of the anticipated hyperactivity. Method

The Ss were 27 male albino rats of the Holtzman strain. All animals were 70 days old at the time of testing. Weights ranged from 300 to $320 \mathrm{~g}$.

Five identical activity boxes served as the apparatus. Each box was $11.5 \times 11.5 \times 12$ in. and constructed of $1 / 2$ in. plywood with $1 / 4$ in. Plexiglas lining the interior walls. A series of 10 photocell units were mounted each with a red filter on two walls of the apparatus. The light sources were appropriately positioned on the opposite walls. There were four lower beams located $2-1 / 2$ in, above a $1 / 2$ in. wire mesh floor whlle the six upper beams were 6-1/4 in. from the floor. Both upper and lower beams were aligned in a row and spaced 4 in. apart. Two separate counters automatically recorded all interruptions of the upper and lower beams. The upper beams were designed to measure vertical exploration such as elongated trunk extensions while the lower beams recorded normal quadruped activity. Testing was done in a darkened, sound attenuated room.

One week before drug administration, all animals were given $1 \mathrm{cc}$ of .3\% gum tragacanth IP and tested $1 / 2 \mathrm{~h}$ later for $30 \mathrm{~min}$. Activity was monitored every $5 \mathrm{~min}$. On the basis of the total activity score from the lower beams, the Ss were rank ordered and dichotomized into two matched groups. During drug administration, the procedure was identical except that the drug group $(\mathrm{N}=14)$ received $20 \mathrm{mg} / \mathrm{kg}$ of magnesium pemoline in the gum tragacanth solution while the placebo animals $(N=13)$ received an equal volume of gum tragacanth. Three days later all animals were again tested under the influence of the placebo injection.

Results

Figure 1 presents the mean activity scores for the pre-drug, drug, and post-drug administrations for both upper and lower beams. An analysis of variance with repeated measures, correcting for unequal $\mathrm{N}$ by a leastsquares solution (Winer, 1962) revealed highly significant interval effects for both upper and lower beams on all three test sessions (range of $F s=25.32-129.20$, $\mathrm{df}=5 / 125, \mathrm{p}<.005)$. For the pre-drug administration, group effects were not significant for both lower and upper beams (Fs $<1.5$, df $=1 / 25, p>.05$ ). During drug administration, the magnesium pemoline group was significantly more active, than the placebo animals in interrupting the lower $(F=29.27, d f=1 / 25, p<.005)$ and upper ( $F=13.45$, df $=1 / 25, p<.005$ ) beams. Moreover, differences were evident immediately, i.e., within the first $5 \mathrm{~min}$ of testing or $35 \mathrm{~min}$ after injection. For the post-drug phase, the drug group exhibited significantly fewer interruptions of the lower beams than the placebo group ( $F=4.57, d f=1 / 25, p<.05$ ). No significant group differences were found in the number of upper-beam breaks during this phase $(F=1.51$, df $=1 / 25, p>.05)$. Discussion

The major results of this study are in essential agreement with Beach \& Kimble (1967) and corroborate the hypothesis advanced by others that a predominant characteristic of magnesium pemoline is its stimulant 
LOWER BEAMS UPPER BEAMS

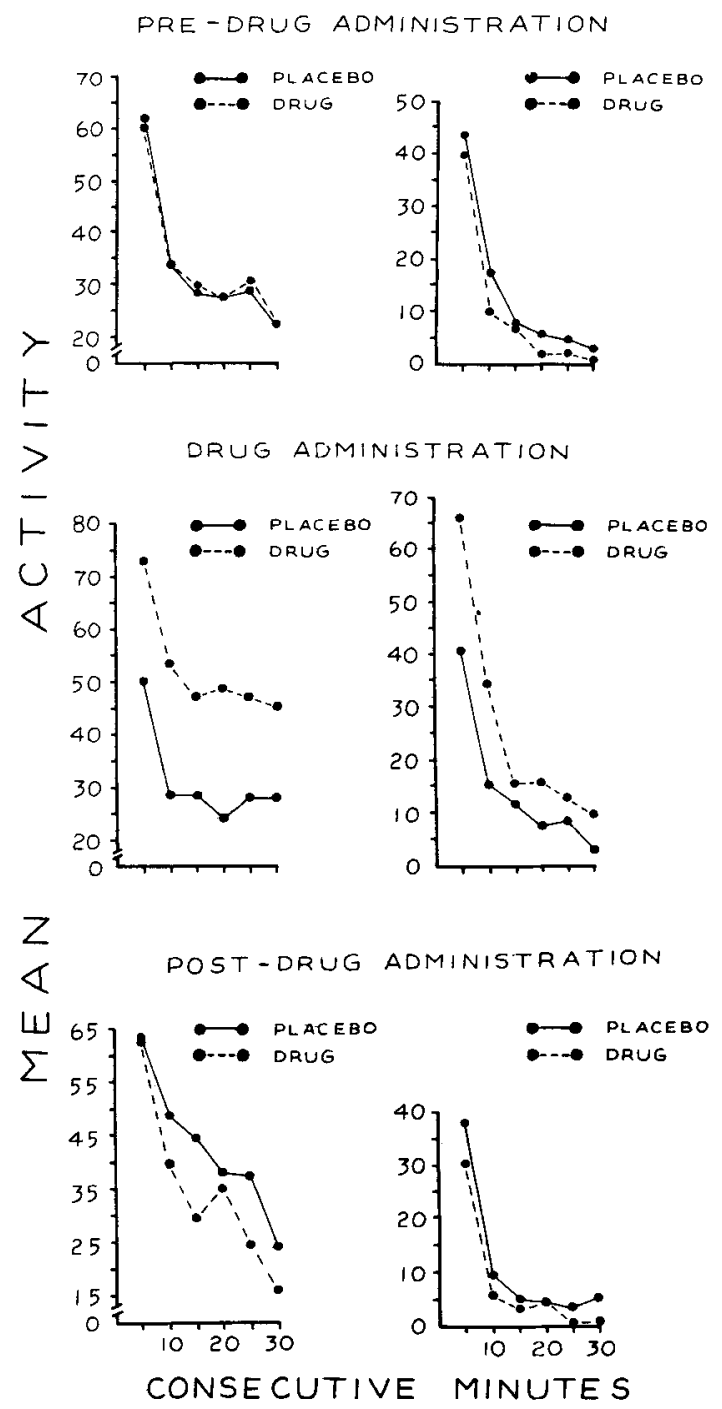

Fig. 1. Mean activity for lower (left) and upper (right) photocell beams during pre-drug (top), drug (middle), and post-drug (bottom) administration. The abscissa is plotted in 5 min blocks.

qualities. In addition the observed increase in spontaneous motor activity occurred almost immediately and before the $50 \mathrm{~min}$ post-injection interval suggested by Beach and Kimble. Perhaps the delay in behavioral activation reported by these authors was due to a procedural artifact. The 45-sec time samples taken once every $20 \mathrm{~min}$ for six trials may have actually masked and delayed the drug's enhancement of overt motor activity. Each $\mathrm{S}$ was only allowed $15 \mathrm{sec}$ of adaptation before a $75 \mathrm{~dB}$ buzzer was presented for a similar 15 sec period. On Trial 1, the post-stimulus phase reflected the consequences of the noxdous buzzer. This resulted in an inhibition of movement, perhaps as a result of adding fear to the motivational complex. It is suggested that on Trial 1 the sequence of testing did not permit sufficient adaptation and that the presence of unconditional emotional responses retarded the drug's action. At the termination of the 4-1/2 min of total test time, the drug's effect was behaviorally evident. This corresponds to the initial $5 \mathrm{~min}$ of the present study.

Three days after the administration of magnesium pemoline, the drug group exhibited significantly less activity than the control Ss while both groups were under the influence of the placebo injection. If this significant decrease in activity is a valid "rebound" phenomenon, it may possibly be explained by postulating the existence of a central homeostatic inhibitory mechanism which limits overt activity after a period of prolonged hyperexcitability. Manto (1967) has recently reported a rebound of parasympathetic dominance leading to reduced motor activity after injection of epinephrine. However, Gelhorn's (1957) suggestion that intense sympathetic arousal induces parasympathetic dominance does not seem applicable to the present study. Lange, Candon, \& Chessin (1962) have reported that the stimulation produced by magnesium pemoline does not resemble that induced by sympathomimetic amines. Therefore, the inhibition must be centrally organized and not attributable to a process in the peripheral nervous system.

\section{References}

BEACH, G., \& KIMBLE, D. P. Activity and responsivity in rats after magnesium pemoline injections. Science, 1967, 155, 698-701.

CYERT, L. A., MOYER, K. E., \& CHAPMAN, J. A. Effect of magnesium pemoline on learning and memory of a one-way avoidance response. Psychon. Sci, 1967, 7, 9-10.

FREY, P. W., \& POLIDORA, V. J.'Magnesium pemoline: effect on avoidance conditioning in rats. Science, 1967, 155, 1281-1282.

GELLHORN, E. Autonomic imbalance and the hypothalamus. Minneapolis: University of Minnesota Press, 1957.

GUROWITZ, E. M., LUBAR, J. F., AIN, B. R., \& GROSS, D. A. Disruption of passive avoidance learning by magnesium pemoline. Psychon. Sci, 1967, 8, 19-20.

LANGE, W. E., CANDON, B. H., \& CHESSIN, M. Metal chelates of oxazolidinones as central nervous system stimulants. J. pharm. Sci, $1962,51,477-480$.

LUBAR, J. F., BOITANO, J. J., GUROWITZ, E. M., \& AIN, B. R. Enhancement of performance in the Hebb-Williams maze by magnesium pemoline. Psychon. Sci, 1967, 7, 381-382.

MANTO, P. G. Blockade of epinephrine-induced decrement in activity by scopolamine. Psychon. Sci., 1967, 7, 203-204.

PLOTNIKOFF, N. Magnesium pemoline: Enhancement of learning and memory of a conditioned avoidance response. Science, 1966, 151, 703-704.

POWELL, B. J., MARTIN, L. K., \& KAMANO, D. K. Magnesium pemoline: Effects of training vs. testing of an avoidance response. Psychon. Sci, 1967, 8, 205-206.

WINER, B. J. Statistical principles in experimental design. New York: McGraw-Hill, 1962.

\section{Notes}

1. This research was supported by a USPHS postdoctoral research fellowship grant from the National Institute of Mental Health (J. J. B.). We should like to thank Dr. Hollis Schoepke of Abbott Laboratories for supplying the drug, Carol Clark for the use of the apparatus, and Karl Emilson for technical assistance.

2. Now at Department of Psychology, Fairfield University, Fairfield, Connecticut. 